\title{
AVENIDA XOAN XXIII. SANTIAGO DE COMPOSTELA (GALICIA, ESPAÑA)
}

\author{
(XOAN XXIII AVENUE, SANTIAGO DE COMPOSTELA. GALICIA, SPAIN)
}

\author{
A. Viaplana y H. Piñón, Drs. Arquitectos; R. Mercadé, Arquitecto \\ ESPAÑA \\ Fecha de recepción: 18-VIII-95

\section{RESUMEN}

Los montes que circundan Santiago nos enseñan que sus formas, leves y romas, se encuentran mal ocultas bajo las piedras de la vieja ciudad. Si entramos por Xoan XXIII las vemos asomar, no sin esfuerzo, entre las rúas Nova y Vella, y bajar, con más de un tropiezo, hasta el rio del fondo.

El proyecto se ha limitado a recuperar las naturales formas de siempre. En el mismo borde del histórico perimetro se ha rehecho un espacio anterior, ahora de piedra, para convertirlo en lugar de acogida y entrada.

Sirve, por añadidura, de pasoy de parada de vehiculos; pero lo esencial ya no es esto. Quizás se trata, sin más, de un espacio abstracto, quieto, previo a las promesas que ofrecenlas inquietas torres del fondo.

\section{Memoria sucinta}

Antecedentes

En los años sesenta se abrió un acceso directo al centro de Santiago de Compostela; ello provocó que por el Norte se rompiera el tejido histórico de la ciudad.

Este nuevo acceso, amplio y desconsiderado, acabó por aglutinar un conjunto de actuaciones urbanas estándar que

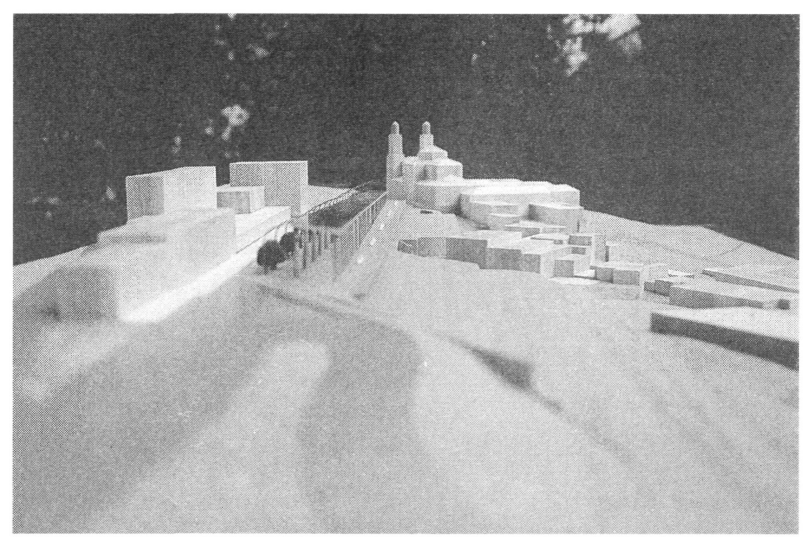

\section{SUMMARY}

The hills surrounding Santiago show that their smooth rounded shapes are not too well hidden under the stones of the old city. if we go into the town through Xoan XXIII Avenue, we can see them crop up, not without effort, between Nova and Vella Streets, and descend, with more than one bump, down to the river at the bottom.

The projet reduces itself to regain the former natural shapes. At the very edge of the historic perimeter, the ancient space has been recovered, now in stone, to make it a place of arrival and welcoming.

It also serves for vehicles to go througt and stop, but now, not only that. It may well simply be an abstract space, standing still, prior to the promise announced by the disturbing towers in the back.

parecían ignorar la cualidad monumental del municipio que los engendraba.

El propósito esencial del Proyecto de Ordenación que nos ocupa es compatibilizar los requisitos funcionales de acceso y acogida con las exigencias ambientales que impone la cualidad histórica de Santiago. Así, la Avenida Xoan XXIII pierde su aspecto suburbano para convertirse en un salón que es entrada simbólica y principal a la ciudad para turistas, visitantes y peregrinos.

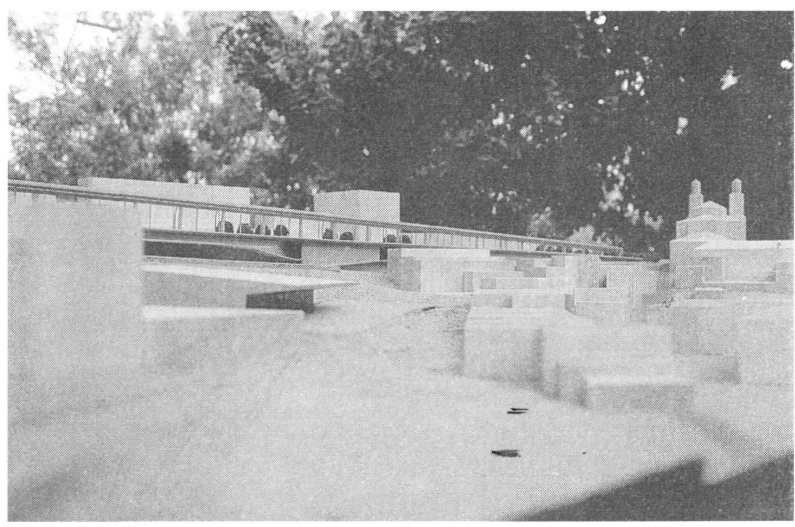




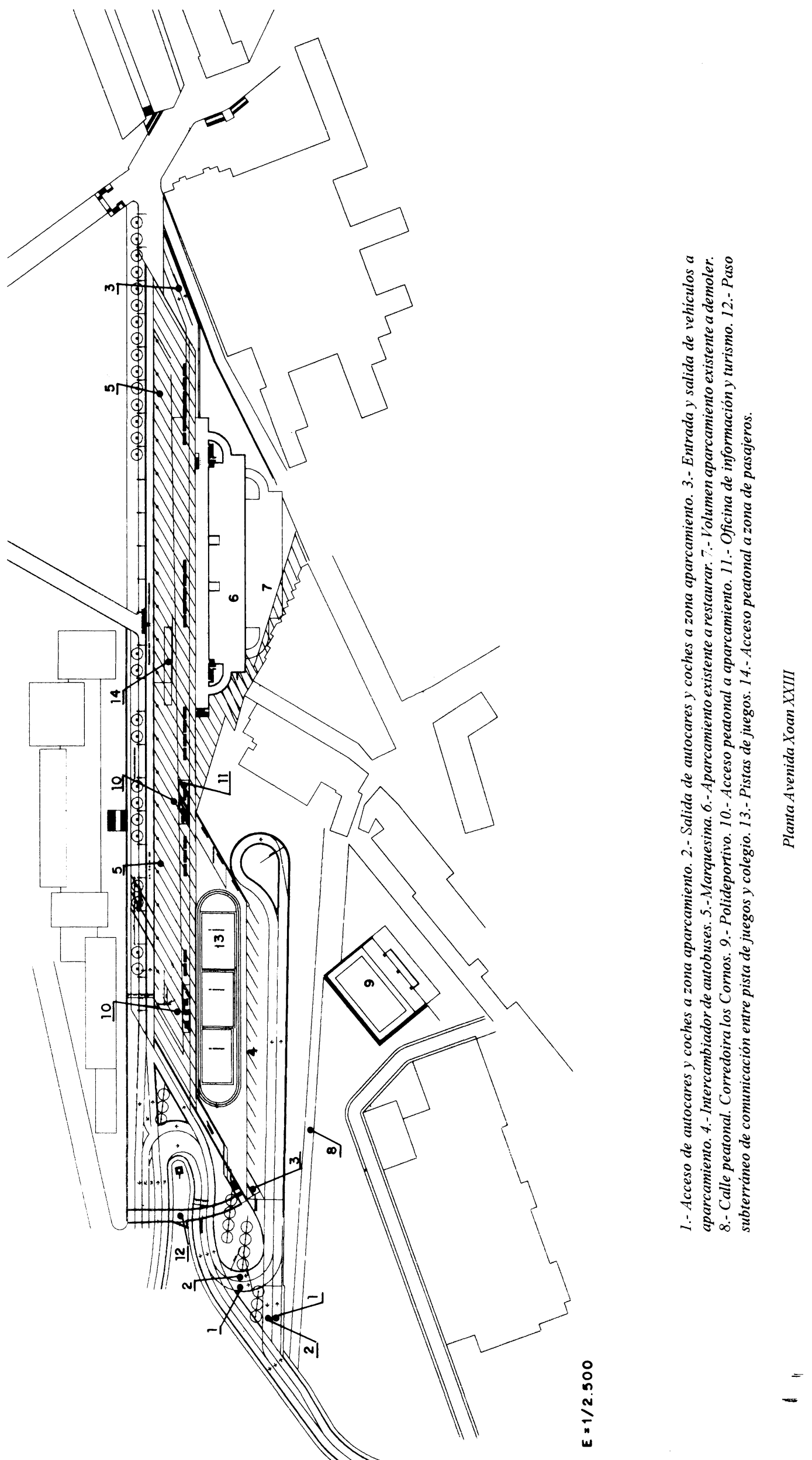




\section{Descripción}

Una rotonda ordena los accesos de autocares al intercambiador de autobuses y coches al nuevo aparcamiento; éste se desarrolla en cuatro niveles, se recorre en una sola dirección con atajos y se comunica por la planta segunda con el existente, funcionando así los dos conjuntamente con una sola entrada y dos salidas. El aparcamiento existente reduce su capacidad al inutilizar la planta de cubierta superior.

En la superficie de la avenida aparecen dos construciones que corresponden a accesos peatonales al aparcamiento, acogiendo una de ellas, conjuntamente con éste, la oficina de información y turismo.

Desde el intercambiador de autobuses se accede, mediante dos rampas, primero a los servicios para pasajeros, consistentes en aseos, cafetería, espera, teléfonos... y, finalmente, a la Avenida Xoan XXIII. Este mismo recorrido sirve para restituir la continuidad entre la rúa Costa Nova a uno y otro lado de la avenida.

En la cubierta de la planta primera del nuevo aparcamiento se prevé la situación de una zona de juegos que conectará, mediante un paso subterráneo, con el Colexio Público al que sirve.

El salón propiamente dicho recibe un tratamiento de superficie que contempla un pavimento granítico, con losas en los pasos de peatones y adoquines mecanizados en las zonas de paso de vehículos. Una marquesina recorre longitudinalmente el salón, protegiendo de la lluvia por medio de una cubierta de vidrio y del sol con unas lamas de acero "corten". Una sucesión de bancos dobles de estructura metálica y lamas de madera y una baranda de acero inoxidable, completan el mobiliario urbano del paseo.
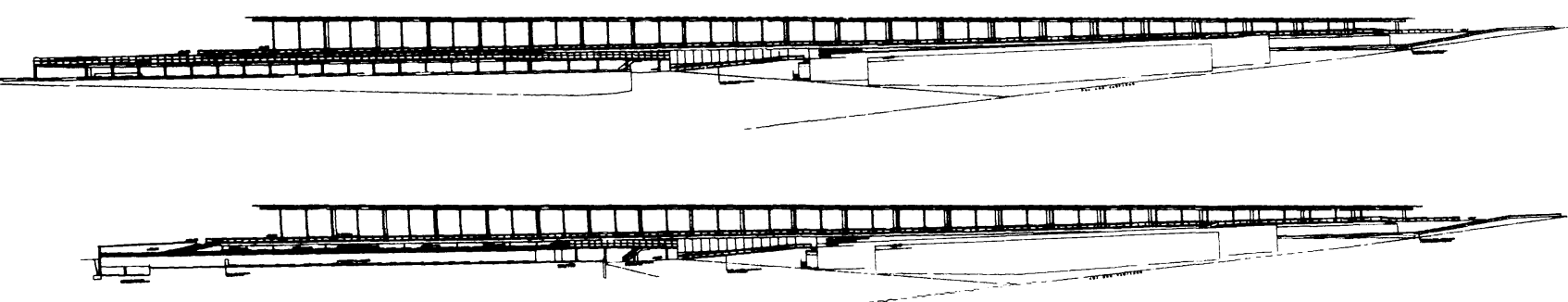

$E=1 / 2.500$

Alzados.

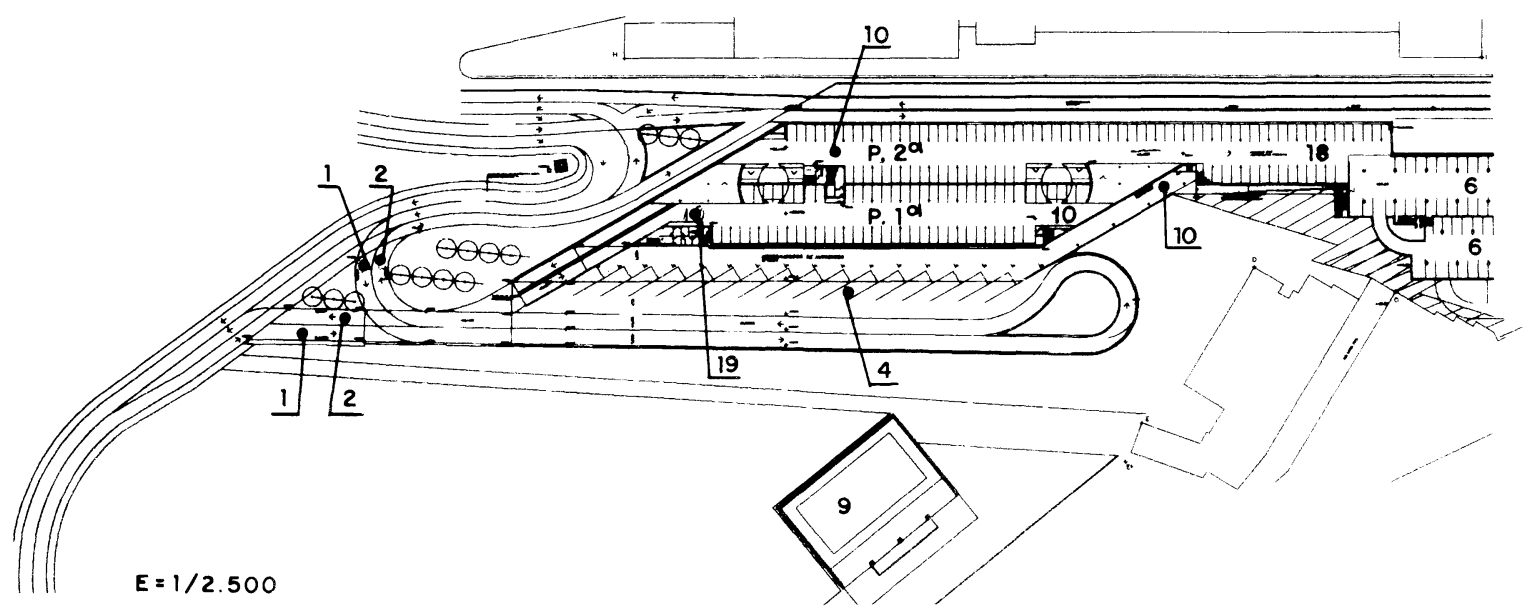

1.- Acceso de autocares y coches a zona aparcamiento. 2.- Salida de autocares y coches a zona aparcamiento. 4.- Intercambiador de autobuses. 6. Aparcamiento existente a restaurar. 9.- Polideportivo. 10.- Acceso peatonal a aparcamiento. 18.- Comunicación entre aparcamientos nuevo y existente. 19.- Oficinas y aseos aparcamiento.

Plantas $1^{a}$ y $2^{a}$. 
66

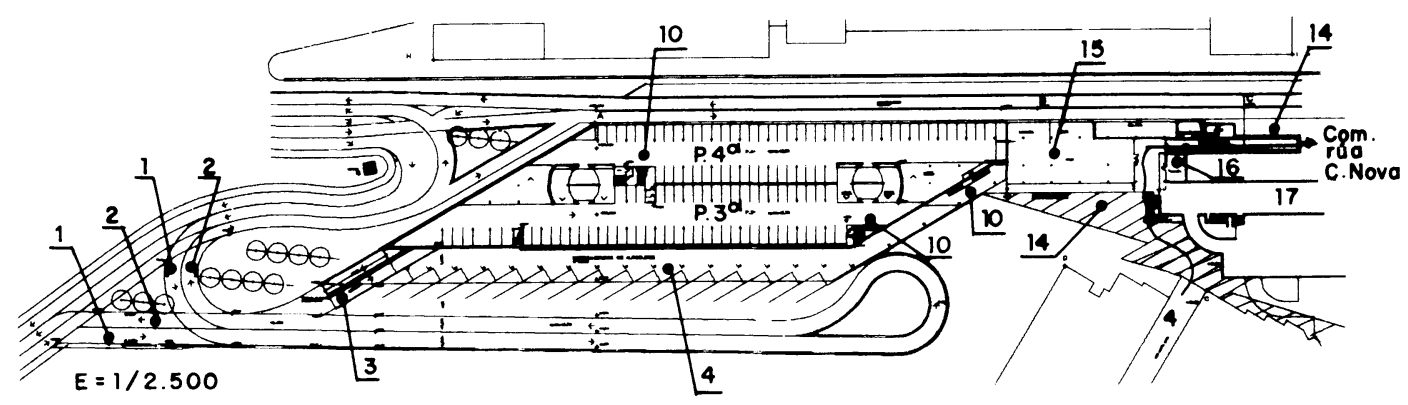

1.- Acceso de autocares y coches a zona aparcamiento. 2.- Salida de autocares y coches a zona aparcamiento. 3.- Entrada y salida de vehiculos a aparcamiento. 4.- Intercambiador de autobuses. 10.- Acceso peatonal a aparcamiento. 14.- Acceso peatonal azona de pasajeros. 15.-Zona de pasajeros (aseos, cafetería, tiendas...). 16.- Telefónica. 17.- Superficie aparcamiento existente ahora para uso peatonal.

\section{Plantas $3^{a} y 4^{a}$.}

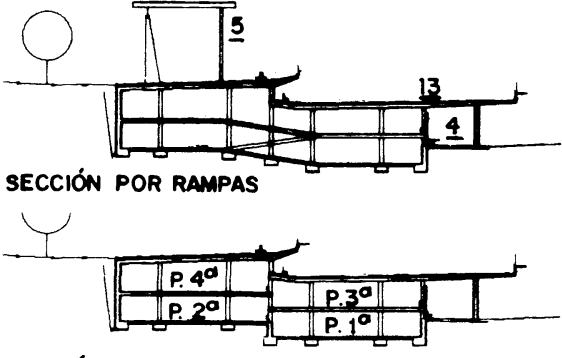

SECCIÓN TIPO
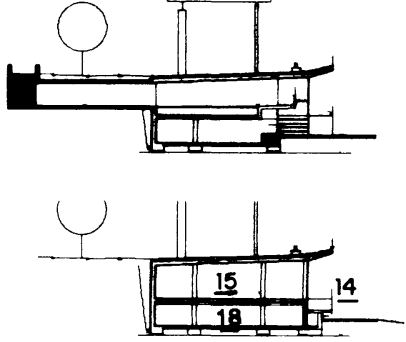

SECCIÓN CENTRO COMERCIAL

$E=1 / 1.000$

4.- Intercambiador de autobuses. 5.-Marquesina. 13.-Pistas de juegos. 14.-Acceso peatonal a zona de pasajeros. 15.-Zona de pasajeros (aseos, cafetería, tiendas...). 18.- Comunicación entre aparcamientos nuevo y existente.

Secciones.

Proyecto de ordenación de la Avda. Xoan XXIII. Santiago de Compostela

\section{Proyecto:}

Estudio:

Empresa Constructora:
Albert Viaplana Veá

Viaplana/Piñón Arquitectos. R. Mercadé Ass

O.C.P. 